\title{
TUMBAS INÉDITAS DE LA NECRÓPOLIS DE OSMA (SORIA) EN EL MUSEO DEL EJÉRCITO
}

\author{
POR \\ JOSÉ IGNACIO DE LA TORRE ECHÁVARRI \\ RICARDO BERZOSA DEL CAMPO
}

\section{RESUMEN - ABSTRACT}

En el presente trabajo pretendemos dar a conocer cinco ajuares funerarios procedentes de la necrópolis de Viñas de Portuguí (Osma, Soria), que ingresaron en el antiguo Museo de Infantería en 1916, y que forman parte actualmente de la colección del Museo del Ejército. El lote está formado por un buen número de armas, destacando las características espadas de antenas atrofiadas, así como elementos de clara raigambre cultural romana. Estos nuevos ajuares permitirán ofrecer una visión de conjunto más completa del cementerio, así como acercarnos al proceso de romanización que sufrió la población de Uxama.

The basic aims of this work is the study of six panoplies from cemetery of Viñas de Portuguí (Osma, Soria), which were acquired by the Infantry Museum (ancestor of the Army Museum of Madrid) in 1916. This set was constituted by several samples of Celtiberian «warriors» weapons. We also shall attempt to study an ensemble of objects with Roman influences. These items allow to explain the Roman acculturation process lived by the Uxama population, with the introduction of new materials in the burials.

\section{PALABRAS CLAVE - KEY WORDS}

Uxama. Necrópolis de Osma. Armamento celtibérico. Ajuares funerarios. romanización.

Uxama. Necropolis of Osma. Celtiberian weapons. Roman acculturation.

\section{INTRODUCCIÓN}

Entre 1913 y 1916 Ricardo Morenas de Tejada, uno de los pioneros en los trabajos arqueológicos en la provincia de Soria (Zapatero, 1968: 57-86), llevó a cabo excavaciones en el cerro de «El Castro», lugar donde se ubica la ciudad de Uxama (Burgo de Osma, Soria). Paralelamente, en dos campañas realizadas en los años 1915 y 1916, compaginó sus trabajos en la ciudad con los de la recién descubierta necrópolis de Osma ${ }^{1}$, emplazada en el lugar conocido como las Viñas de Portuguí (Morenas de Tejada, 1916; Taracena, 1941: 125).

1 En 1985 se descubrió otra necrópolis relacionada con Uxama, con una cronología similar a la de Viñas de Portuguí, la de Fuentelaraña. Campano y Sanz Mínguez (1990: 65-73) indican como esta necrópolis debe ser incluida entre las más tardías del oriente de la Meseta, «..de un momento muy avanzado de la etapa celtibérica donde aún se mantienen las tradiciones indígenas -elementos de adornos, armas, cerámicas, ritual funerario- si bien algunas piezas metálicas y fundamentalmente cerámicas denuncian ya claras influencias romanas» (Las fechas bajas vienen sugeridas por la presencia de la empuñadura de un puñal biglobular, una fíbula derivada de La Tène y 2 hebillas en omega, (Campano y 


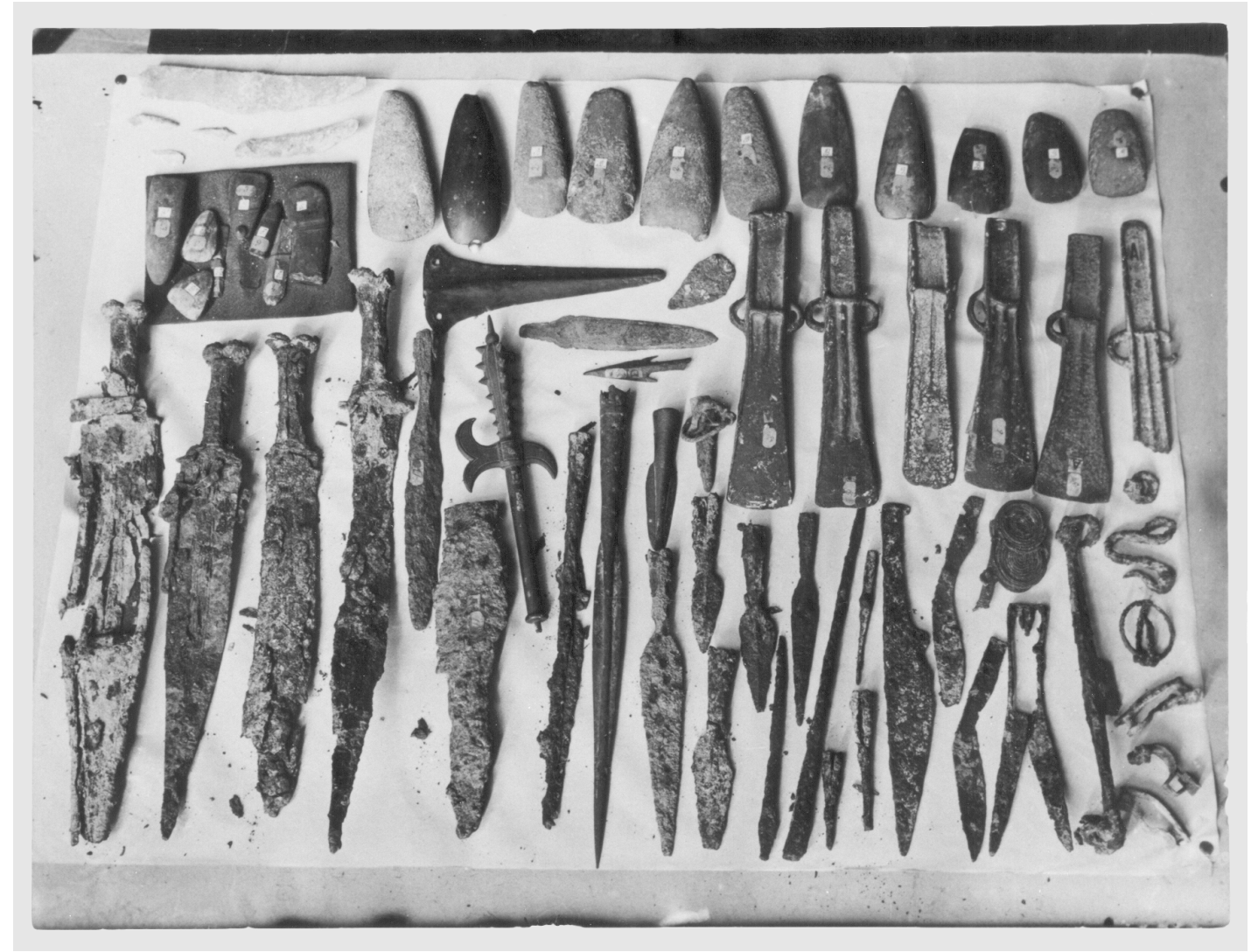

Fig. 1. fotografía de época de los materiales de Uxama junto con otros de procedencia diversa. (Foto Museo del Ejército).

Con los objetos encontrados en el cerro de Uxama y con los ajuares funerarios de las más de 800 tumbas exhumadas en la necrópolis, - la mayoría de ellos de «guerreros celtibéricos»-, realizó una exposición en Madrid en su casa de la calle Alberto Aguilera. De esta forma, los ajuares fueron montados en una serie de «cartones» ${ }^{2}$ con la intención de que fueran adquiridos por el Ministerio de Instrucción Pública y que pasasen a engrosar los fondos de diferentes museos (Zapatero, 1968: 85). Sin embargo muchos de ellos se dispersaron al acabar en manos de coleccionistas particulares, por lo que gran parte de los restos han permanecido inéditos y no han posibilitado su adecuado estudio científico. Casos similares se dieron en otras necrópolis excavadas por Morenas de Tejada en esa época como La Requijada y Quintanas 3 (Gormaz, Soria), o por otros como Cerralbo o Cabré que lo hicieron en Arcóbri-

Sanz Mínguez, 1990: 71, fig. 6 y 73). Argente (1994: 306) indica como esta necrópolis pertenece al último momento del periodo celtibérico, coincidiendo con García Merino en una cronología entorno a los siglos III-I a.C, y por tanto contemporánea a la de Portuguí (García Merino, 1995:14).

2 Así aparecían denominados en el Inventario del Museo de Infantería en 1916 y así los definió Cabré (1917: 89-93) al referirse a cada uno de los ajuares que ingresaron en el M.A.N. Parece ser que no era infrecuente en la época que los materiales arqueológicos fuesen sujetos a soportes rígidos como cartón o madera con cuerdas o alambres para ser expuestos.

3 Morenas de Tejada excavó durante los años 1914 y 1915 las necrópolis de incineración de la Requijada de Gormaz, descubriendo 1.125 enterramientos (Morenas de Tejada, 1916; Zapatero, 1968: 62), y la de Quintanas de Gormaz, con «más de 800 enterramientos» (Zapatero, 1968: 17). En referencia a esta última Taracena afirmaba: «..de la que no ha publicado noticia alguna y se desconoce (...) el paradero de la mayor parte de los hallazgos» (Taracena, 1941: 138). 
ga, Aguilar de Anguita, Alpanseque, Luzaga, Hijes, Turmiel, Océn, etc. De todas ellas se conservan en colecciones de diferentes museos una pequeña parte de los ajuares más espectaculares, casi siempre «militares» ${ }^{4}$, no documentándose convenientemente las que no presentaban armamento al no concedérselas la misma importancia. Esto conllevó además como ha señalado Quesada (1997: 43-44), a que se sobrevalorase el «peso» a nivel porcentual del conjunto de las armas halladas. La realidad de los trabajos arqueológicos realizados en necrópolis celtibéricas en fechas más recientes parece confirmar que el porcentaje de las tumbas que contuvieron ajuares armamentísticos debió ser mucho menor (Lorrio 1997: 149, fig. 58).

De esta forma, procedentes de las excavaciones realizadas en la necrópolis de Osma, el Museo Arqueológico Nacional adquirió por R. O. de 31 de julio de 1917, doce urnas junto con los ajuares de quince enterramientos (Mélida, 1917: 132), al mismo tiempo que el Museo Arqueológico de Barcelona obtenía otras catorce tumbas más (Bosch Gimpera, 1931: 173-185). Sin embargo, un año antes de estas adquisiciones, el Museo de Infantería de Toledo había procedido a la compra de seis «cartones» al «cesionario» de Morenas de Tejada, Luis García Ochoa $^{5}$. Dichos «cartones» estaban constituidos como veremos a continuación, por unos pocos adornos de bronce como fíbulas, espirales, fragmentos de broches de cinturón, etc, junto con un número mayor de armas: lanzas, regatones, cuchillos y espadas de antenas.

Sin tener total seguridad de que todas las piezas que entraron formando parte de cada ajuar correspondan a una misma tumba y admitiendo la posibilidad de que se produjeran manipulaciones para montar puntualmente algún «cartón», el hecho de que junto a las piezas más significativas ingresaran asociadas a ellas otras menos relevantes consideradas «sin clasificar» o «indeterminadas», permite admitir que al menos en su mayoría se trate de conjuntos cerrados. Además, dentro del conjunto de las tumbas conocidas de esta necrópolis, el grupo del Museo del Ejército mantiene en general bastante coherencia. Hay que recordar en cualquier caso, que en una situación semejante se encontrarían las piezas que entraron en el M.A.N, o en el Museo Arqueológico de Barcelona, tratadas como procedentes de conjuntos cerrados (Bosch Gimpera, 1931: 173).

\section{LA NECRÓPOLIS DE OSMA}

Según Morenas de Tejada (1916) se trataba de un cementerio de incineración sin estelas, en el que se hallaron más de 800 enterramientos que consistían en simples hoyos abiertos en la tierra en los que se colocaban vasos con cenizas y el ajuar funerario ${ }^{6}$. Llegó a distinguir tres categorías de enterramientos aunque no determinó el número de tumbas pertenecientes a cada una, por lo que resulta difícil realizar cálculos de tipo social. Estos grupos estaban constituidos por «tumbas de guerrero», caracterizadas por la presencia de «..espada, filetes de caballo, cu-

4 Entre todas ellas se excavaron unas 10.000 tumbas. Sin embargo el porcentaje de conjuntos cerrados conocidos en relación al total de los descubiertos no supera el 5\% (Lorrio, 1997: 147 y 149, fig. 58), tratándose en la mayoría de los casos de ajuares armamentísticos.

5 En el Leg. 13/ Exp. 22 del Archivo Histórico del Museo del Ejército se encuentra la carta que certifica la venta de las armas «..sacadas en las excabaciones [sic] hechas en la Necropolis Iberica de Usama-Partido judicial del Burgo de Osma.» Está firmada por García Ochoa «cesionario» del «..concesionario del Gobierno D. Ricardo Morenas de Tejada, ex-diputado a Cortes.». No obstante, la intención inicial del Museo de Infantería fue la de contactar en 1914, por medio del Capitán Florencio Latorre, con la Comisión de Excavaciones encargada de llevar a cabo los trabajos arqueológicos en Numancia, integrada por José Ramón Mélida y Blas Taracena entre otros, a la que se «suplicaba» que contribuyese «..con su generoso desprendimiento a aumentar los objetos de carácter militar del Museo.» (Barroso 1997: 358). Esto no se llevó a cabo ya que afortunadamente en esas mismas fechas se estaba construyendo el Museo Numantino, lo que impidió la dispersión de la colección.

6 Lorrio (1995, 599 y 1997) llegó a identificar 40 ajuares de los 800 que exhumó Morenas de Tejada en la necrópolis de Osma, todos ellos «militares». 

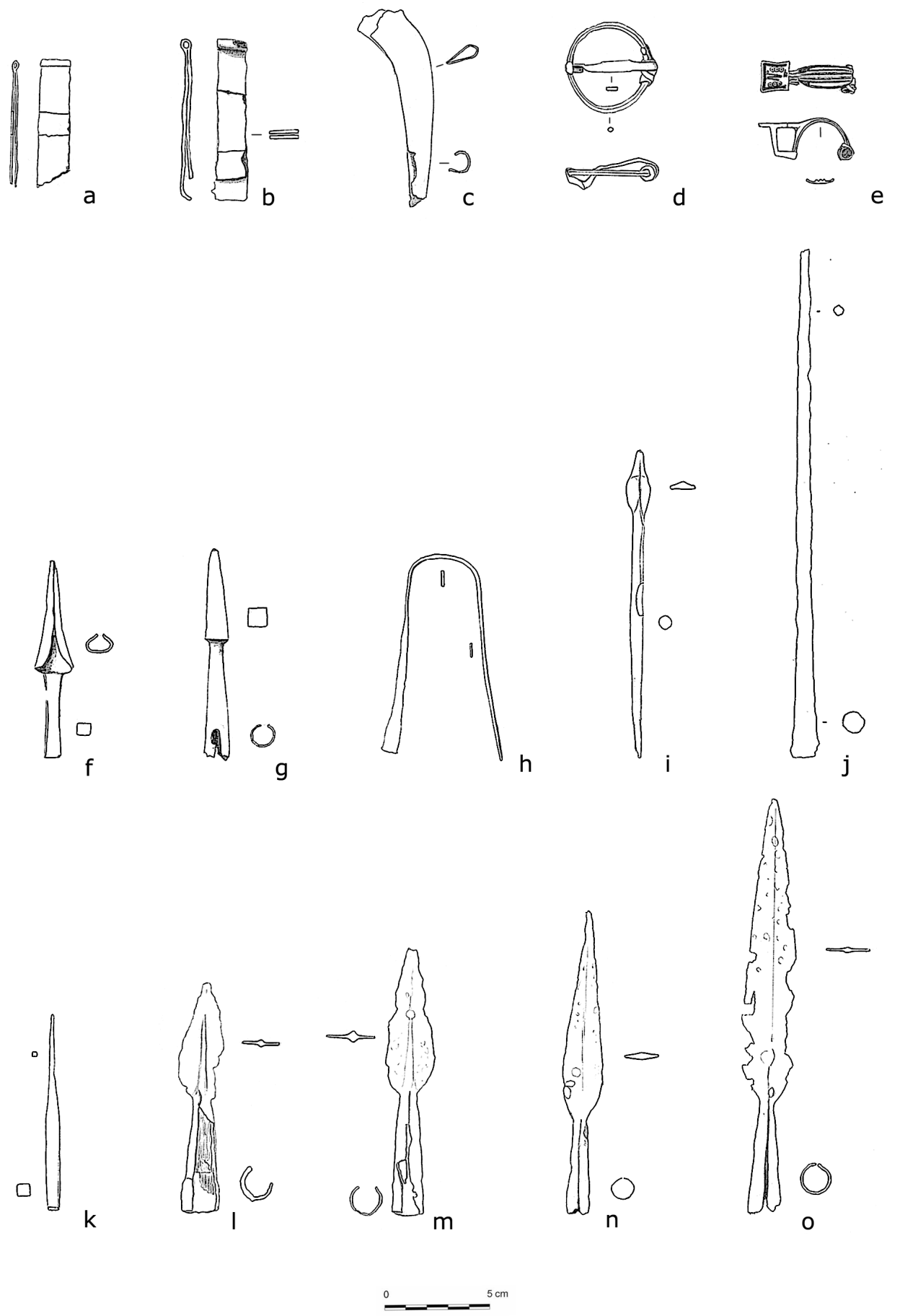
fíbula anular hispánica; e: fíbula de pie alzado; f-g: Puntas de proyectil romano; h: muelle de tijera; i: falarica; j: pilum; k: pincho; l-o: puntas de lanza (todos en hierro excepto ambas fíbulas). 


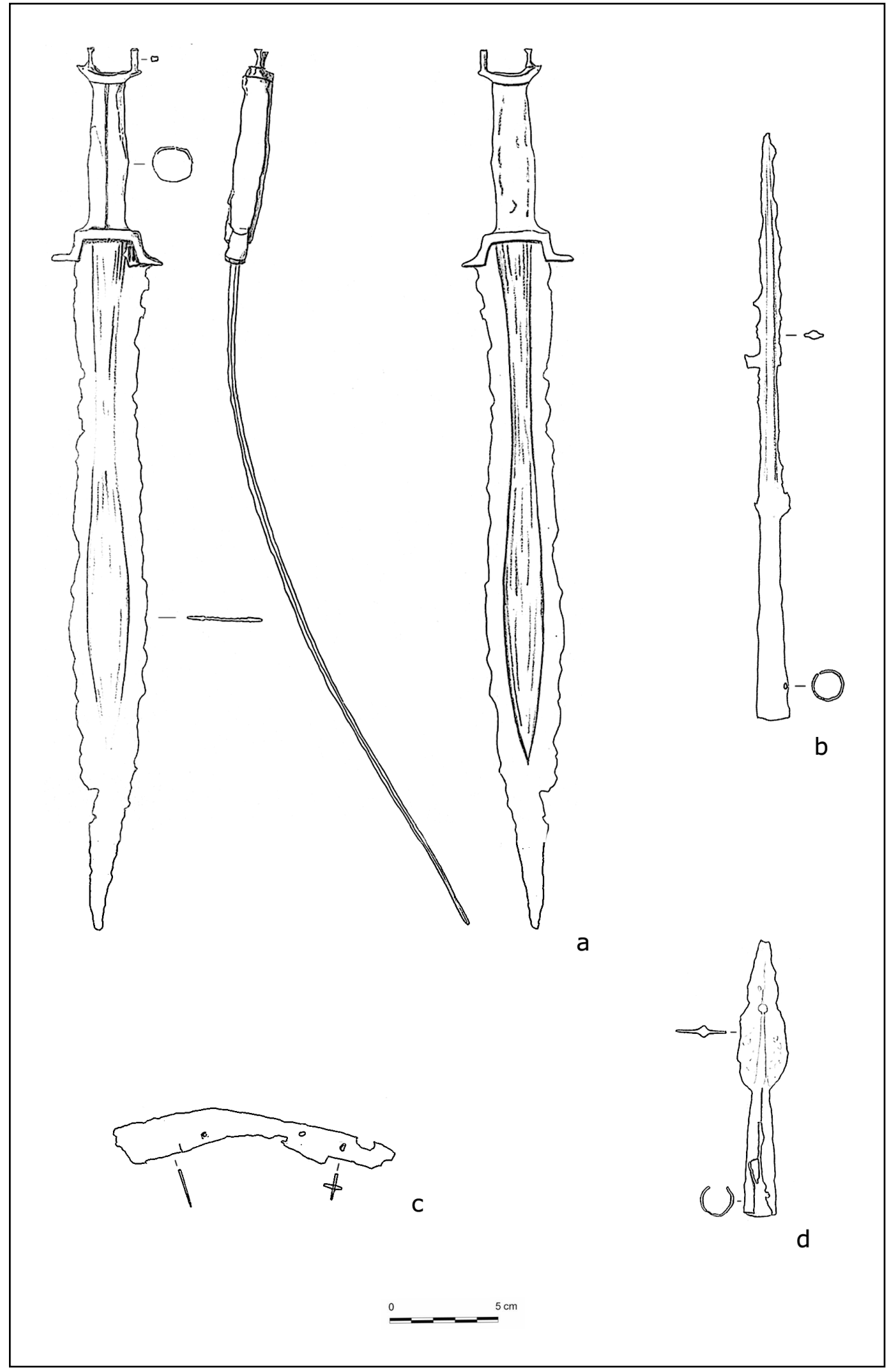

Fig. 3. Conjunto 1 (cartón 1). a: espada de antenas; b: punta de lanza; c: cuchillo curvo; d: fíbula de pie vuelto (todos los objetos fabricados en hierro). 
chillo, lanza y bolas simbólicas..», «tumbas de niño», tan sólo con «..huesecillos cremados y alguna sortijilla..», y «tumbas de mujer», que contaban principalmente con «..adornos de bronce en espiral y tocados capilares..». No obstante, su excavador afirmaba que Osma era una necrópolis «..poco pródiga en adornos de mujer, tanto que podríamos considerarla de un eminente carácter guerrero, viril...», documentando un total de setenta espadas y puñales.

Los tipos de espadas que más abundaban en esta necrópolis eran los de antenas, los de «la Tena» [sic] y los puñales biglobulares. Incluso halló una «falcata curva» (Morenas de Tejada, 1916: 608).

La cronología de la necrópolis fue establecida por su excavador entorno al siglo II a. C. al reconocer una «..manifiesta influencia romana en las señales de un arte más adelantado.» (Morenas de Tejada, 1916: 608). Estas fechas fueron precisadas por Mélida (1917: 133) y Bosch Gimpera (1931: 180), quienes la dataron entre el siglo III a.C. y la destrucción de Numancia (133 a.C.), y más adelante por García Merino, que centró su cronología entre los siglos III y I a.C, e incluso apunta la posibilidad de que sobrepasase el cambio de Era (García Merino, 1995: 15). Estas dataciones vienen a reflejar una utilización prolongada de este cementerio, con las tumbas más antiguas con elementos representativos de los momentos finales del periodo Celtibérico Pleno (siglo III a.C.) ${ }^{7}$, caracterizadas por la presencia de espadas de antenas. Otro grupo que pertenecería a la fase de conquista romana ${ }^{8}$, con espadas de tipo La Tène y ajuares muy parecidos a los de la necrópolis de Numancia (en fase de estudio). Por último, una serie de sepulturas algo más tardías, que debemos considerar celtíbero-romanas, a la que pertenecería el «cartón» $n^{0} 6$ del Museo del Ejército.

\section{LOS AJUARES DEL MUSEO DEL EJÉRCITO}

Como hemos mencionado anteriormente, ingresaron en el museo seis «cartones» que contenían un total de sesenta y dos objetos metálicos, no yendo acompañados de las urnas cinerarias, ya que como era común en la época se separaban las cerámicas del resto del ajuar ${ }^{9}$. Posteriormente, las piezas fueron retiradas de los expositores, sin fotografiar ni catalogar, y mucho menos habiéndose estudiado los objetos. Quedaron entonces la mayoría de ellos confundidos con todo tipo de piezas procedentes de otros yacimientos de diversa cronología y adscripción cultural (fig. 1). De los objetos originales de la necrópolis de Osma sólo quedó constancia en el libro de registro elaborado a su entrada, en el que aparecían diferenciadas las piezas por «cartones» y se definían algunas de sus características y dimensiones. Ha sido esta documentación la que nos ha permitido reconstruir los antiguos conjuntos de modo fiable y presentarlos con buena parte de su composición original. No obstante se mostrarán por separado aquellas piezas que no han podido ser adscritas con seguridad a ninguno de ellos (fig. 2).

Lo que sí es cierto es que todos los cartones presentaban armas y por tanto, habrían formado parte del grupo que Morenas de Tejada consideró como «tumbas de varón guerrero». Cuatro de ellas portaban ejemplares de espadas de antenas atrofiadas, además de un número considerable de puntas de hierro pertenecientes a diferentes tipos de armas enastadas. En ninguna de ellas había puñales, si bien Lorrio (1997: 391) indicaba como en todas las tumbas

7 A este momento cronológico, o fase IIb de Lorrio (1997: 183), adscribe este autor las tumbas de Osma 2, 4, 8, 9 , 10, 11 y 14 del M. A. B.; y las 2, 4, 11, 12, 13, 16 y 18 del M.A.N. (Lorrio, 1997: tabla 2).

8 Fase III de Lorrio (1997: 188) en la que incluye las tumbas de Osma 1 y 14 del M.A.B. y la 13 del M.A.N. (Lorrio, 1997: tabla 2).

9 De hecho, las urnas que entraron en el M.A.N. y en el M.A.B. no está demostrado que pertenezcan a los conjuntos adquiridos por dichos museos (Bosch Gimpera, 1931: 173). 
por él estudiadas aparecía un puñal o una espada, lo cual no deja de ser un dato significativo de la selección realizada con estos ajuares ${ }^{10}$.

\section{Inventario de los cartones}

A continuación presentamos la trascripción parcial del inventario ${ }^{11}$ existente en el Museo del Ejército en el que aparecen los citados «cartones». Por razones de espacio, no se incluirá la descripción mas o menos detallada que se da en el documento de algunos objetos, como por ejemplo las dimensiones, lo que nos sido de gran ayuda a la hora de poder identificarlos.

Cartón 1: a) Espada de antenas, b) lanza con nervio central, c) cuchilla, d) lanza, e) resto de cinturón o de fíbula, f) y h) fíbulas, la h es de bronce, g) parte de un cinturón (adorno) quizá fíbula. (fig. 3)

Cartón 2: a) Lanza o cuchillo, b) espada de antenas, c) no se sabe, d) clavo de cinturón o roblón de espada, e) abrazadera o corredera de cinturón, f) regatón de lanza, y g) regatón de lanza unido a una fíbula petrificada. (fig. 4)

Cartón 3: a) Espada de antenas, b) lanza, c) resto de un bocado de camas rectas, d) contera de una lanza, e) corredera de cinturón, f), j) y h) fragmentos de armas o de sus vainas, y g) adorno de dama celtibérica. (fig. 5)

Cartón 4: a) Espada de antenas, b) lanza pequeña o hierro de pilum, c) chapa de cinturón grabada, d) tijera, e) y h) restos de fíbulas, f) clavo de cinturón, g) navaja o cuchillo de hierro, y j) anillo (tal vez de un bocado o de una espada). (fig. 6)

Cartón 5: a) Flecha (hierro de pilum, dardo), b) lanza (idem), c) y d) se ignora, e) flecha (hierro de pilum, dardo), f) se ignora, g) sin clasificar, h) cuchillo, i) sin clasificar, j) y k) sin clasificar, 1) sin clasificar (fíbula), m) parte de fíbula, n) pica (punta de flecha), o) lanza, p) pica (punta de flecha), y q) sin clasificar.

Cartón 6: a) Insignia, b) Lanza, c) «dige» de bronce, d) brazalete de bronce, e) sin clasificar, f) resto de un espejo (mango), g) y h) sin clasificar, i) y j) fragmentos de..., y k) anillo de bronce. (fig. 7)

La media de objetos por tumba es de 8 elementos, coincidiendo con los datos recogidos por Lorrio (1997), excepto el cartón 5, que ingresó compuesto por 17 piezas.

\section{Ajuares Celtibéricos}

Cuatro son los ajuares que hemos considerado como celtibéricos; los pertenecientes a los «cartones» 1, 2, 3 y 4 (figs. 3 a 6). Dado que hay objetos que no se pueden adscribir con seguridad a ninguno de ellos, una vez expuesto el inventario hemos optado por presentarlos en función de los tipos identificados y no de los ajuares, ya que la información significativa que aportan como conjuntos cerrados será abordada posteriormente.

Espadas de antenas atrofiadas. No cabe duda de que constituyen el grupo de armas más destacadas de Uxama. Las que se conservan en el Museo del Ejército (fig. 8) presentan la empuñadura compuesta por una sola lámina de metal que recubre la espiga, con la unión por

10 Morenas de Tejada (1916: 608) hablaba de setenta espadas y puñales, que estarían presentes tan sólo en el 8\% de las enterramientos, de los que Lorrio (1997: 391) llegó a documentar, a partir de diferentes publicaciones, un total de 40 ajuares, todos «militares».

11 Nos limitamos a transcribir tan sólo las identificaciones que en el inventario original se hicieron de los objetos a su ingreso, contenido en el Leg. 13/ Exp. 22 del Archivo Histórico del Museo del Ejército. 


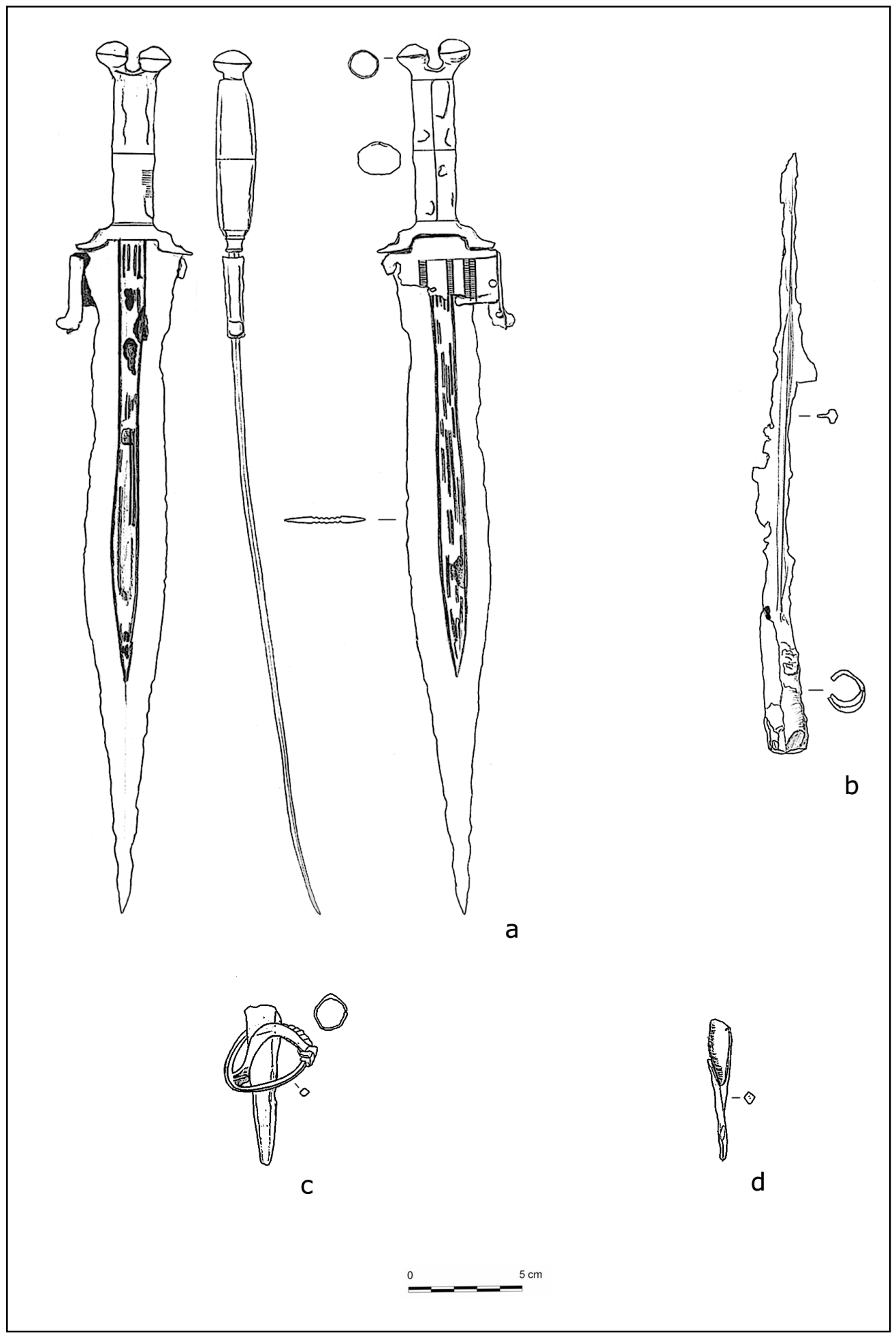

Fig. 4. Conjunto 2 (cartón 2). a: espada de antenas; b: punta de lanza; c: fíbula anular hispánica fundida a un regatón; d: regatón (todos los objetos fabricados en hierro excepto fíbula en bronce). 


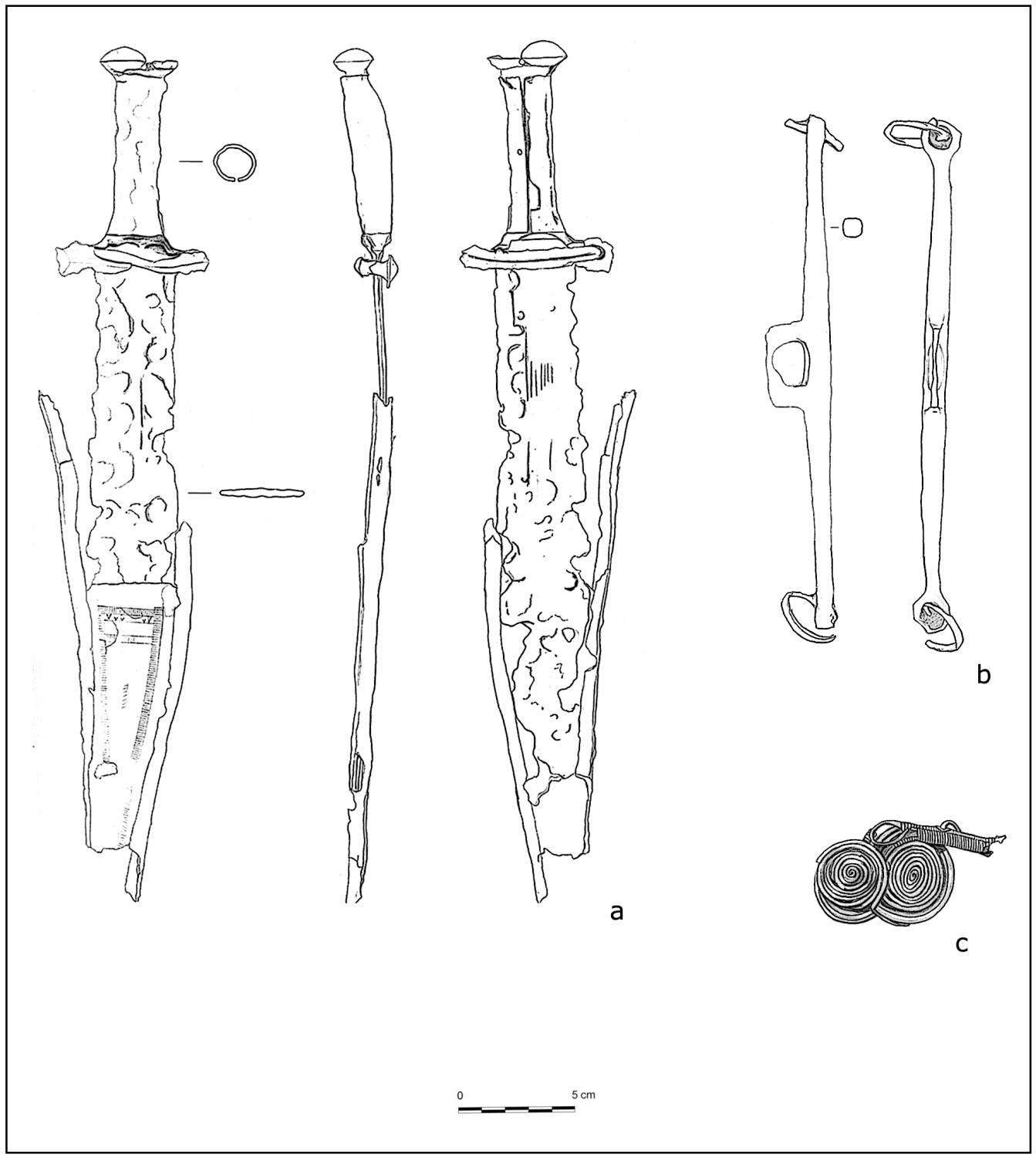

Fig. 5. Conjunto 3 (cartón 3). a: espada de antenas; b: cama recta de arreo de caballo; c: aguja con espirales (a y b de hierro, c de bronce).

el reverso del arma y con los dos remates de las antenas con la típica forma lenticulada carenada (Quesada, 1997: 221). Las hojas son rectas, con una longitud total que oscila entre los 39 y los $46^{\prime} 5 \mathrm{~cm}$, de doble filo, y mesas y acanaladuras por ambas caras. Sin embargo, al presentar sus hojas forma pistiliforme y gavilanes acentuados, algo que es característico de los ejemplares más evolucionados, resultan un híbrido entre los tipos Atance y Arcóbriga de E. Cabré (1990: 123-124) o V y VI de la clasificación de Quesada12 (1997: 220), pudiendo

12 Son tipológicamente idénticas a los ejemplares de Osma presentes en el Museo Arqueológico Nacional, en el Museo Arqueológico de Barcelona y en el Museo Numantino, recogidos por Quesada (1997: 852) y considerados por él como tipo Arcóbriga ó VI y la hibridación Atance con tendencia a Arcóbriga (V-VI). 
ser fechados a finales del siglo III e incluso inicios del II a.C. (Cabré, 1990: 123-125; Cabré y Baquedano, 1997: 258; y Quesada, 1997: 220-221 y 852).

Al poco tiempo de su ingreso en el museo se conservaban prácticamente completas todas las vainas, realizadas en hierro forjado, aunque son pocos los restos existentes actualmente. Casi todas presentan decoraciones incisas con motivos rectilíneos en las cantoneras, así como en alguna anilla de suspensión de la vaina.

La asociación de las espadas de antenas atrofiadas con lanzas y cuchillos según Morenas de Tejada (1916: 608), era la que definía a las tumbas de guerrero. Esta se da en los conjuntos 1 y 4 , si bien en los números 2 y 3 no aparecen cuchillos, aunque existen dos fragmentos de ejemplares afalcatados sin adscipción que pudieron haber pertenecido a estas tumbas.

Armas enastadas. Como ocurre en el resto de necrópolis del área celtibérica y en particular en el Alto Duero, son las armas ofensivas más numerosas. Se trata de puntas de hierro de tamaños y formas muy variados (lanzas, jabalinas, pila,...). Suele aparecer una por tumba, excepto en el conjunto 1, en el que se dan dos ejemplares, y en el cartón 5, que como veremos a continuación tiene una problemática particular.

La variedad de tipos representados es significativa:

Dos lanzas de mayores dimensiones, de 29.6 y $30.5 \mathrm{~cm}$, de enmangue tubular y de nervio central marcado, a las que les falta casi en su totalidad la mesa de la hoja (figs. 3 y 4 )

Otras dos puntas de lanza de dimensiones un poco menores $(16.3$ y $22.7 \mathrm{~cm})$, también de enmangue tubular, nervio central marcado y mesas. Son adscribibles a las variantes VIIBa y VIIBb de Quesada (1997: 377), y ya fueron documentadas en otros enterramientos de la necrópolis de Osma. Por su tipología, estas puntas bien pudieron pertenecer a los cartones 3 y 4 , que en origen tuvieron armas enastadas, aunque en el inventario no quedaron reflejadas sus dimensiones y características (fig. 2).

Tres puntas de jabalina de cubo corto y nervio marcado, con unas dimensiones de 14.3 $\mathrm{cm}, 11.7 \mathrm{~cm}$ (con la punta rota) y $12.8 \mathrm{~cm}$, conservando aún esta última restos de la madera del astil en el cubo (fig. 2).

Una jabalina de punta piramidal maciza de $11,1 \mathrm{~cm}$ y enmangue tubular (fig. 2)..

Una punta pequeña plana, formada a partir de la prolongación de la espiga de hierro de $16,6 \mathrm{~cm}$ (fig. 2).

Por último, una vara de hierro maciza de $27,8 \mathrm{~cm}$, que no conserva la punta, y que parece haber formado parte de un pilum (fig. 2).

Llegados a este punto es digno de reseñar la singularidad del «cartón $\mathrm{n}^{\circ} 5$ », ya que ingresó en el museo compuesto por seis puntas de arma enastada inventariadas como lanzas, pila, flechas, dardos y picas. No se conoce ninguna tumba en la Celtiberia en la que aparezcan tantos ejemplares juntos y de tipos tan variados. Aunque no podamos precisar cuales fueron los objetos originales que integraron este «cartón», el hecho de que las denominaciones fuesen tan diferentes, nos hace pensar que se trataba de un grupo bastante heterogéneo. Por eso creemos que bien pudieron ser seleccionados para realizar una panoplia con la que «ilustrar» a los cadetes en el conocimiento del armamento antiguo ${ }^{13}$.

Cuchillos. Los hay de dorso recto y curvo. Los ejemplares curvos de los cartones 1 y 4 (figs. 3 y 6) están casi completos y aparecen asociados a armamento. Además, hay otros dos fragmentos de hoja que quedaron «sin clasificar» y que completaron alguna de las otras panoplias como se ha dicho. Aunque han sido considerados en ocasiones como armas por ir asociados a estas en los ajuares (Lorrio 1997), lo cierto es que hay que contemplar la posibi-

13 La adquisición de piezas de la necrópolis de Osma por parte del antiguo Museo de Infantería se realizó con la intención de que estas sirviesen de «..ilustración a los jóvenes que aquí educamos para la carrera de las armas» (Leg. 13, Ex. 39 del Archivo Documental del Museo del Ejército). 
lidad de que tuviesen más un carácter de herramienta de uso personal o doméstico que de arma en el sentido estricto (Taracena, 1954: 262; Pérez Casas, 1990: 120).

También existe un ejemplar de cuchillo recto, de grandes dimensiones $(26.7 \mathrm{~cm})$ y un solo filo, adscrito al cartón 5, así como una cacha de bronce sin adscripción, que conserva los remaches empleados para fijarla al enmangue.

Fíbulas. Morenas de Tejada (1916: 607) señalaba la presencia de «fíbulas de pie, naviformes, etc, el más común es el de las armoniosas fíbulas hispánicas de bronce y de hierro...». En el inventario existen lagunas a la hora de la identificación de estas piezas ya que a veces, quien se encargó de hacer su descripción en el museo las denominó, con bastantes dudas, como «broches». Por eso no podemos adscribir la mayoría de las conservadas a un ajuar concreto. Entre las que se conservan hay una de pie vuelto alzado (fig. 2), con el pie en forma de plato cuadrado decorado con pequeños círculos hechos con troquel y granetti. Se trataría del tipo 7d de Argente (1994: 78), al que este autor daba una cronología del siglo III a.C. Curiosamente esta es la única pieza del conjunto publicada por Lenerz-de Wilde en su estudio sobre la Iberia Céltica (1991: fig. 202).

Otros ejemplares de fíbulas aparecidos son dos anulares hispánicas (una de ellas en el conjunto $n^{\circ} 2$, que se encuentra fundida a un regatón, fig. 2), un fragmento incompleto de otra anular con parte del resorte, y el puente de hierro de una fíbula de inspiración laténica a la que le falta el pie (fig. 1).

Broches de cinturón. En el inventario se hacen algunas referencias a estos objetos, de los que Morenas de Tejada (1916: 607) decía que «existen en abundancia: son de bronce, rectangulares, con esbeltos punzones decorados geométricamente...». Lo cierto es que sólo se conserva una pequeña chapa de hierro rectangular que fue definida como «chapa de cinturón grabada», aunque con certeza no lo es. En nuestra opinión se trata de una frontalera de arreo de caballo, por lo que será incluida en el apartado siguiente (fig. 4).

Arreos de caballo. Suele ser relativamente frecuente la aparición de elementos de arreo en tumbas con armamento (Lorrio 1997: 235 y 237). La frontalera que acabamos de mencionar presenta decoración incisa de dos círculos a modo de ruedas, con radios y triángulos inscritos, yendo acompañada de una espada de antenas y una punta de lanza(fig. 6). Esta asociación se repite también en el conjunto 3 donde una cama recta de arreo de $25.6 \mathrm{~cm}$ de longitud apareció junto a una espada de antenas atrofiadas, una punta de lanza y un «adorno de dama celtibérica» (fig. 5).

Elementos de vestimenta. El adorno femenino citado en el párrafo anterior es de los que Morenas de Tejada identificaba como típicos de tumbas femeninas (1916: 608). Esto podría plantearnos de nuevo dudas acerca de la adecuada adscripción de este objeto, teniendo en cuenta que aparece en un ajuar de los que el propio excavador calificaba como de «guerrero viril». Sin embargo, en la tumba 10 de Osma del M. A. B. también aparece un ejemplar de este tipo en un ajuar armamentístico (Bosch Gimpera, 1931: 177). Lorrio recoge a su vez varias tumbas de la necrópolis de La Mercadera con armas asociadas a elementos considerados tradicionalmente como «femeninos» (Lorrio, 1997: 132, fig. 54), y nosotros mismos podemos confirmar este extremo en la necrópolis de Numancia, por lo que no es de extrañar su presencia en esta tumba.

Este elemento de adorno «femenino» se trata en realidad de una aguja con adorno de espirales, variante 9A2 de Argente (1994: 96), realizada a partir de un vástago rectangular al que se enrolla un fino hilo plano de bronce que permite la sujeción de los extremos de las cuatro espirales que la componen. De no estar inutilizado intencionadamente por motivos rituales, estarían distribuidas de forma simétrica a ambos lados del vástago (fig. 5).

Tijeras. Como suele ser habitual en las necrópolis del Alto Duero y en otras tumbas de la necrópolis de Osma, se documentan tijeras de hojas paralelas. Sólo se inventarió un ejemplar casi completo en el cartón 4 (fig. 6), formando parte de un conjunto con armamento, asocia- 


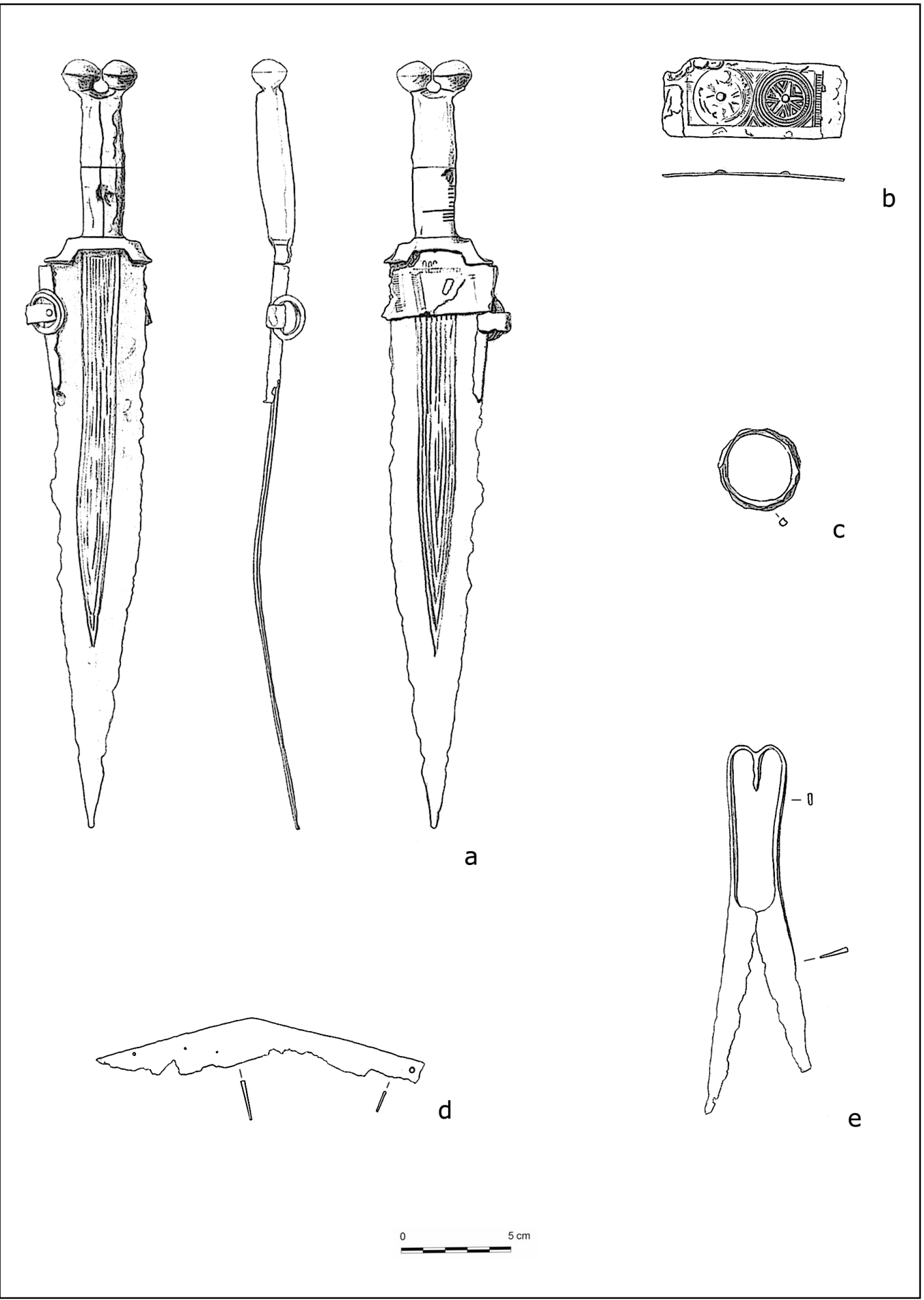

Fig. 6. Conjunto 4 (cartón 4). a: espada de antenas; b: frontalera de arreo de caballo decorada; c: anilla; d: cuchillo curvo; e: tijeras (todos de hierro). 


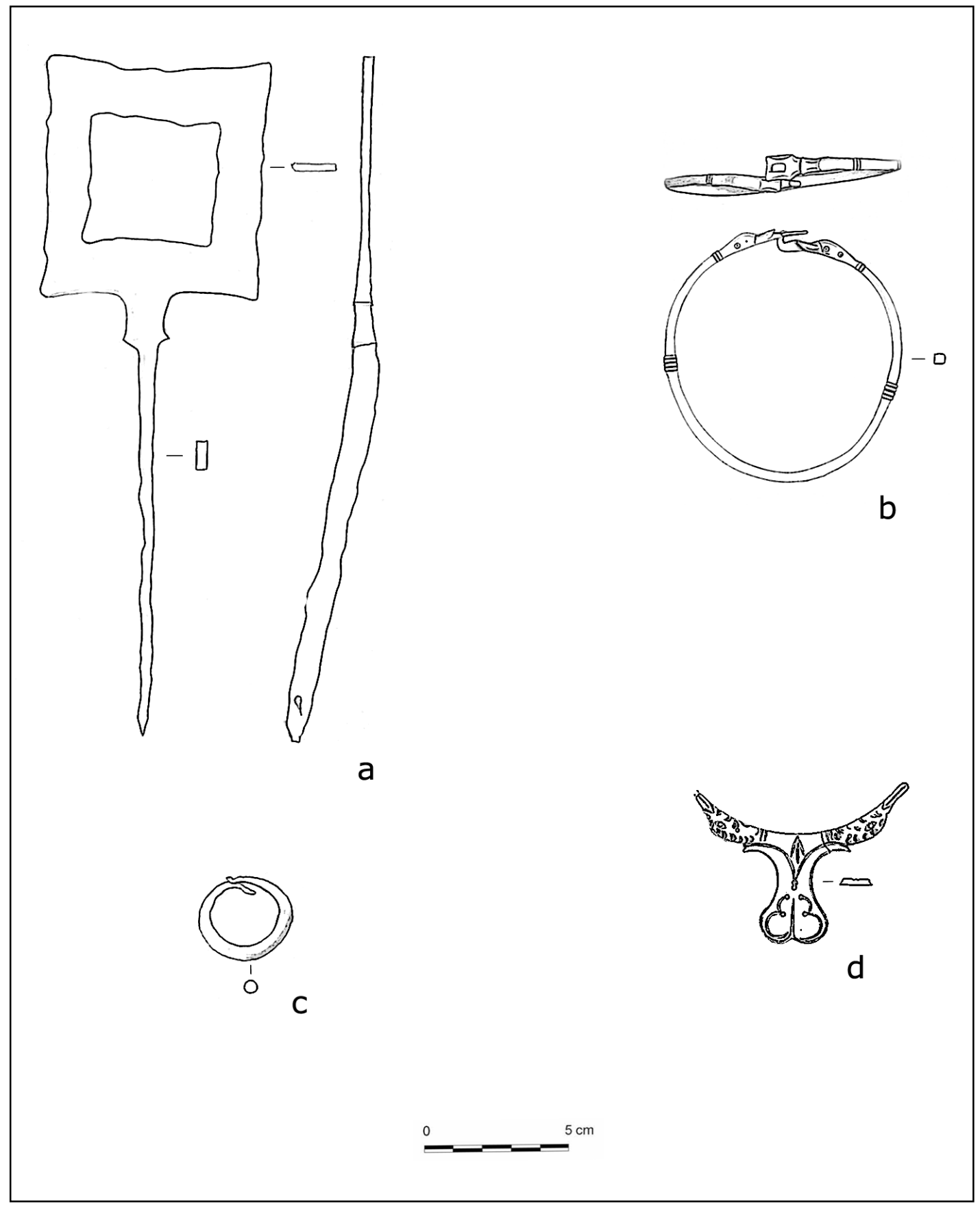

Fig. 7. Conjunto 6 (cartón 6). a: objeto indeterminado; b: aro de estrigilo; c: arete; d: asa de trulla. (todos de bronce excepto a). 
ción que se repite en otras tumbas de Osma y es común en necrópolis del ámbito Celtibérico (Lorrio, 1997: 233). También se conserva un muelle de tijera y un fragmento de hoja de otro ejemplar que en su día pasaron desapercibidos y por tanto nos es imposible relacionarlos con algún conjunto concieto.

Presillas. De entre los objetos que no fueron identificados en el inventario, son reconocibles tres presillas de sujeción, que tradicionalmente se han venido considerando como pinzas de depilar. Una está fabricada en bronce y dos en hierro, estando una de estas últimas decorada con líneas incisas (fig. 2).

Respecto a la asunción de estos objetos como presillas, diremos que dada su morfología es difícil pensar que pudieran cumplir la función de pinzas de pilar adecuadamente. Hay que recordar que habitualmente estas piezas presentan pequeños anillitos «abrazando» las dos patillas. El deslizamiento de este elemento hacia la zona distal de la pieza produciría el efecto de presión y no, la directamente ejercida con los dedos sobre la parte central como en una pinza corriente. Por tanto, su funcionamiento y uso seria distinto al de la depilación. Probablemente dada su fragilidad, su misión estuviese más relacionada con la sujeción o fijación de elementos de poco peso y grosor como una tela fina.

Podaderas. Por último, resulta interesante el fragmento de una podadera de enmangue tubular que no se ha podido adscribir a ningún ajuar. Utensilios similares se han encontrado en otras necrópolis en tumbas con armas (Lorrio, 1997: 233-234), habiendo sido incluso consideradas como tales. En nuestra opinión, deberían ser interpretadas simplemente como herramientas.

\section{Ajuar Celtíbero-romano}

El cartón $n^{\circ} 6$ merece una mención especial, ya que ingresó en el Museo compuesto por una punta de lanza, tres fragmentos de un anillo de bronce, una «especie de dije» o colgante de bronce, tres elementos «sin clasificar», junto con otros tres objetos en cierto modo excepcionales a los que dedicaremos especial atención: un aro de bronce que ha sido tradicionalmente considerado como «brazalete», un curioso objeto de hierro definido como «insignia», y una pieza de bronce rematada por prótomos de ánades, y que fue tenida por el «mango de un espejo» (figs. 7 y 9). Todas ellas son piezas singulares dentro de lo que podríamos considerar cultura material celtibérica, al no haberse documentado antes objetos similares. Morenas de Tejada ya señalaba la exhumación de algunas piezas notables con «estilizaciones de aves y de caballos, y otros serpentiformes con combinaciones muy artísticas» (Morenas de Tejada, 1916: 607). Como veremos al analizarlas más detalladamente, sus características formales y su funcionalidad parecen corresponder a un momento avanzado de utilización de la necrópolis, en torno al siglo I a.C, época en la que ya se registran claras influencias del mundo romano en la cultura celtibérica.

El primero de estos objetos es realmente el aro de suspensión de un estrigilo. Su sección es cuadrangular y remata en ambos extremos por sendas cabezas de ánade moldeadas y decoradas con líneas incisas para resaltar el pico, así como con pequeños círculos a troquel para marcar los ojos. Presenta además una serie de resaltes dispuestos en dos grupos de cuatro, uno a cada lado del aro, y un sencillo sistema de cierre imbricado desarrollado a partir de los picos de las aves, consistente en un pequeño gancho que se alojaría en la parte pasiva del enganche. Ejemplares casi idénticos aparecieron en el nivel iberorromano de Azaila (Beltrán Lloris, 1976), así como en el campamento romano de Cáceres el Viejo (Ulbert, 1984: 72 y 74), donde están bien documentados en el primer cuarto del siglo I a.C. Fueron descritos por Cabré como «aretes de bronce con cabezas de cisnes» (1926: 7) y posteriormente por Beltrán como posibles «torques» (Beltrán, 1976: 170). Sin embargo Ulbert los identificó como aros 
de estrigilo, formando parte de este instrumento en otros hallazgos similares del mundo romano (Ulbert 1984: 84). También han sido documentados en contextos funerarios del occidente de la península Itálica, entorno a los siglos II-I a.C., como en la necrólpolis de Castiglioncello, en Etruria (AA. VV. 1999: 82, fig. 24).

La strigilis era un instrumento por lo general metálico, compuesto de un mango (capolus) y de una parte semicircular (ligula), usado tanto por hombres como por mujeres para quitarse el sudor, la suciedad, aplicarse ungüentos, aceites, etc. También se usaba después de tomar el baño en las termas o para la relajación muscular tras haber realizado ejercicio en la palestra. Estos objetos llevaban un aro de suspensión que permitía colgarlos en la pared, portarlos en la mano, suspenderlos del cinturón, etc. La pieza que hemos descrito sería precisamente este elemento de suspensión.

El siguiente objeto que integra este ajuar, erróneamente identificado con el mango de un espejo, es un asa de bronce perteneciente a un pequeño cazo metálico o trulla, de unos $10 \mathrm{~cm}$ de diámetro. Está hecha a partir de una placa de bronce recortada y rematada por dos ánades, esta vez opuestos, con un sentido dual y de simbología ctónica. La decoración es de tendencia geometrizante, pero además denota el gusto por el grafismo plano, por la simetría y por los contornos curvilíneos. El anverso de la pieza aparece decorado con una serie de incisiones que definen los detalles del pico y de los ojos, reflejando una sensibilidad estética en las formas y un gran detallismo en la decoración que se puede además advertir en el plumaje de los ánades, realizado a partir de pequeños rebajes en el bronce. En la parte inferior del enmangue se pueden distinguir unas líneas curvas incisas, rematadas en puntos, que conforman unos motivos vegetales esquemáticos a modo de trébol. Estas alusiones vegetales combinadas con los motivos zoomorfos muestran además un enlace armonioso de la decoración con el soporte al que se ajustan.

La trulla era un recipiente metálico, con capacidad para un decilitro, empleado a modo de pequeño cazo para el trabase de líquidos. Han aparecido algunos ejemplares completos, por ejemplo, en las excavaciones que A. Floriano realizó en Caparra, aunque en este caso se tratase de una pieza de plata hallada formando parte del ajuar de una tumba (Cerrillo y Herrero, 1992: 14), o en las termas romanas de Bath, donde han sido considerados como pequeños recipientes utilizados para realizar libaciones (Cunliffe, 1993: 21). Piezas parecidas con decoraciones aviformes similares, fueron frecuentemente empleadas como asas de recipientes metálicos en esa época. En el campamento republicano de Cáceres el Viejo (Cáceres) aparecen curiosamente asociadas a aros de estrigilo (Ulbert 1984: lam. 13), pudiendo estar en relación con el uso de estos, empleándose los recipientes para el trasbase de aceites y ungüentos para su posterior aplicación.

El último de los objetos «curiosos» el conjunto 6 es una pieza de hierro forjado de forma cuadrangular ( $83 \times 83 \mathrm{~mm})$, con los lados exteriores ligeramente cóncavos y con un vano central. Presenta una larga prolongación de sección rectangular con un engrosamiento en la parte superior de la misma para hacer de tope al astil y un orificio a modo de pasador en el extremo inferior, concebido para fijar la pieza a un enmangue de madera. A su ingreso en el museo fue definida como una «insignia» militar, aunque Pastor (1998: 44), al apreciar su tamaño, la interpretó como una insignia personal de composición abstracta, concebida para dar dignidad a su portador. Sin embargo, no se conocen en la Península Ibérica ejemplares similares. Las piezas consideradas como signa equitum, vexillium o estandartes, que son conocidas formalmente a través de la iconografía monetal y cerámica, presentan formas muy diferentes a esta. Por lo general los motivos son zoomorfos, como el jabalí en la Galia, el lobo, el toro androcéfalo y el águila para el mundo romano, o los báculos de distinción rematados en prótomos de caballo en el ámbito celtibérico (Jimeno, 1994). Estos objetos, de los que en la necrópolis de Numancia se ha documentado un interesante conjunto, se caracterizan por presentar enmangues tubulares, estar realizados mayoritariamente en bronce, y representar símbolos generalmente identificables y no abstracciones. Ninguna de estas tres carac- 


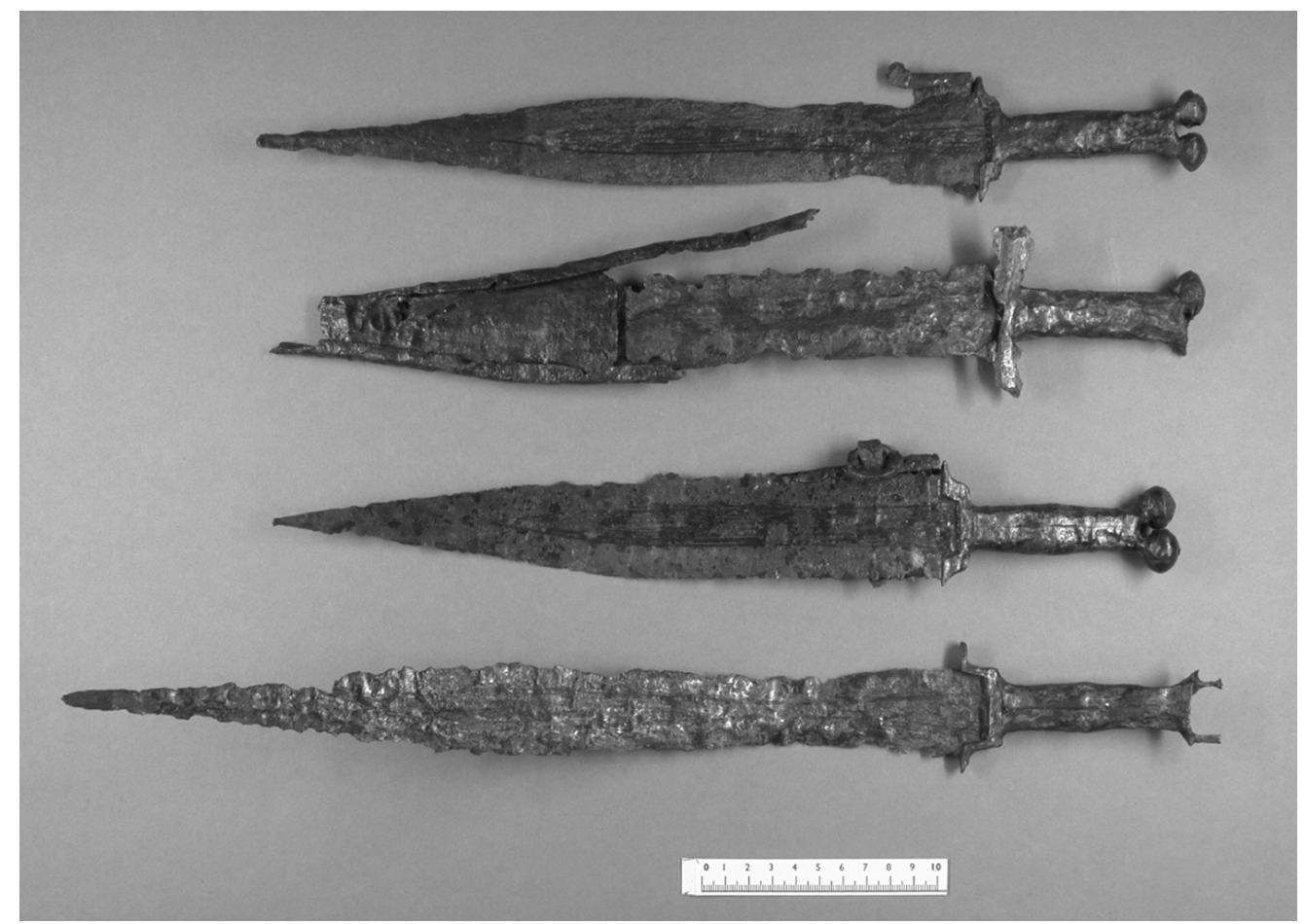

Fig. 8. Conjunto de espadas de antenas atrofiadas de las tumbas del Museo del Ejército (Foto Museo del Ejército).

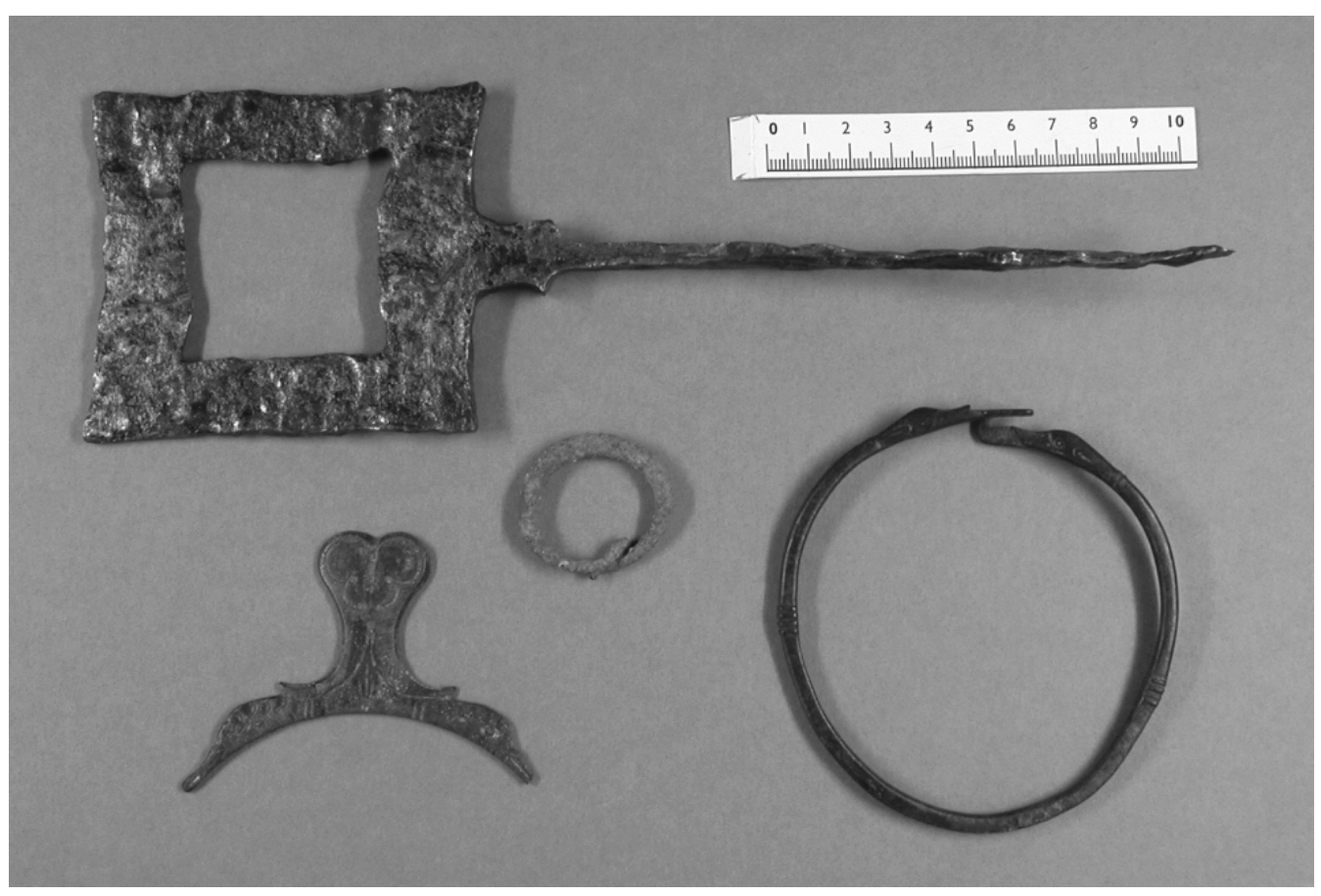

Fig. 9. Objetos pertenecientes a la tumba 6. (Foto Museo del Ejército). 
terísticas las cumple la pieza de Uxama. Este hecho, unido a los elementos a los que aparece asociada, nos hace pensar que hubiese tenido una funcionalidad completamente distinta;, aún por determinar.

Todos estos objetos en un ajuar funerario único, junto a los citados fragmentos de anillo, el colgante o pendiente de bronce y la punta de lanza, estarían reflejando un momento de fusión ideológica y ritual entre el mundo celtibérico y el romano. Por un lado, por el hecho de aparecer en un espacio funerario celtibérico, en el que aún se mantiene el ritual de incineración con la típica deposición en un hoyo. La aparición de una lanza en el ajuar puede entenderse como una reminiscencia de la herencia cultural indígena. Por otro lado, los elementos descritos que se incorporan a este ritual están vinculados, dentro del ámbito romano republicano al que pertenecen, al aseo e higiene personal. Esto supone además la sustitución de algunos elementos empleados tradicionalmente en el ajuar funerario como las armas, por otros a los que se confiere ahora mayor importancia tal vez inmersos en un nuevo concepto de «prestigio» social.

\section{CONCLUSIONES}

Pretendemos con estas líneas hacer notar una vez más la problemática que presentan, por su «historia», los ajuares de las necrópolis celtibéricas excavadas a inicios del siglo XX, y los de Osma en particular, al darnos una visión muy sesgada del conjunto de los enterramientos de estos cementerios. Por eso creemos que a la hora de realizar valoraciones de tipo social apoyadas exclusivamente en ellos, estas deben hacerse cuando menos, con cierta cautela.

Tras analizar los nuevos ajuares que aquí se han presentado, a excepción del $\mathrm{n}^{0} 5$ por las razones expuestas, los demás parecen gozar de coherencia en relación con el resto de los conocidos hasta el momento de la necrópolis de Osma. Por tanto, aunque incompletos en parte, consideramos que existe suficiente fiabilidad como para considerarlos como conjuntos cerrados.

Sumando estas nuevas cinco tumbas al conjunto conocido, intentaremos completar la periodización cronológica de la necrópolis de Osma. Diremos en primer lugar que se observan diferencias entre las tumbas que presentan espadas de antenas atrofiadas por un lado y de tipo La Tène por otro, resultando en nuestra opinión un tanto forzado asumir que se trate de tumbas contemporáneas.

Las tumbas con presencia de espadas de antenas, híbridas entre los tipos Atance y Arcóbriga (Quesada 1997: 220-221), aparecen acompañadas de elementos considerados más antiguos, como por ejemplo un broche de cinturón tipo «céltico» de tres garfios (tumba 9 M.A.B.). En este sentido estamos de acuerdo con la adscripción cronológica inicial dada para la necrópolis en épocas recientes, es decir, el siglo III a.C. A este momento pertenecerían los cuatro primeros «cartones» del Museo del Ejército que se presentan en este trabajo.

Por otra parte, en aquellos ajuares en los que la espada que aparece es la de tipo La Tène, estas van relacionadas con elementos considerados más modernos como fíbulas en omega (Mélida, 1918: 133; y Lenerz-de Wilde 1991), o ejemplares de fíbulas de pie fundido al puente, del tipo 8B de la clasificación de Argente (1997: 84). Son los casos por ejemplo de las tumbas 13 y 14 de Osma depositadas en el Museo Arqueológico de Barcelona, muy parecidas además a alguno de los ajuares exhumados en la necrópolis celtibérica de Numancia, actualmente en estudio. A esta se le atribuye una cronología que va desde el tránsito de los siglos III al II a.C. hasta a la caída de la ciudad en el 133 a C., no habiéndose documentado ningún ejemplar de espada de antenas atrofiadas (1993: 131).

Por último, resulta especialmente interesante el «cartón» 6 (fig. 5) ya que con las reservas lógicas ya expresadas, se podría apreciar a través de él la romanización progresiva de la población de Uxama. Esta influencia puede observarse en otros aspectos al menos desde 
inicios del siglo I a.C., en la acuñación de monedas de bronce en la propia ciudad entre el año 100 a.C. y el 45 a.C. (García Merino, 1995: 14), o en su participación activa en las guerras sertorianas (83-72 a.C.).

Este ajuar, inmerso ya en el mundo celtibero-romano, supondría la «confirmación» de una tendencia reflejada con anterioridad en los ajuares de las tumbas, que parece documentarse en las últimas fases de las necrópolis indígenas. Nos referimos a la sustitución progresiva de elementos como las armas, a los que tradicionalmente se ha conferido mayor importancia al considerarse objetos de «prestigio», por otros que reflejarían un cambio en el ritual funerario, reflejo de cambios a nivel social. Como se ha dicho, la presencia de una punta de lanza asociada a este conjunto denotaría aún reminiscencias de la tradición indígena, difícil no obstante de abandonar por completo. Este extremo, también fue detectado por Argente y Jimeno (1978: 38) en momentos bastante posteriores, al estudiar varios enterramientos en urna pétrea (de clara filiación romana) exhumados en la necrópolis romana de la ciudad, y que fueron fechados en el s. I de la Era.

\author{
JoSÉ IGNACIO DE LA TORRE ECHÁVARRI \\ Museo del ejército de Madrid \\ RicARDo BERzosa del CAMPO \\ Dpto. de Prehistoria, Universidad Complutense de Madrid
}

\title{
BIBLIOGRAFÍA
}

AA.VV. (1999): Castiglioncello. La necropoli ritrovata.Cento anni di scoppere e scavi (1896-1997).

Argente Oliver, J.L. (1994): Las fíbulas de la Edad del Hierro en la Meseta Oriental. Valoración tipológica, cronológica y cultural, (Excavaciones Arqueológicas en España, 168). Madrid, Instituto de Conservación y Restauración de Bienes Culturales.

ARgente, J.L. y JiMENO, A. (1977): «Tres tumbas de incineración de época romana, halladas en Uxama (Osma, Soria)». Celtiberia, $n^{\circ}$ 53: 29-40. Soria.

BARRoso, S. (1997): «Armamento celtibérico de Uxama en el Museo del Ejército». Militaria, Revista de Cultura Militar, nº 10: 357-364. Madrid, UCM.

BeltrÁn LloRIs, M. (1976): Arqueología e Historia de las ciudades antiguas del Cabezo de Alcalá de Azaila. Teruel, Librería General.

BosCh Gimpera, P.(1931): «Troballes de las necrópolis d’Osma i Gormaz, adquirides pel Museo de Barcelona». A.I.E.C. MCMXXI-MCMXXVI. Barcelona.

CABRÉ, J. (1926): «Los bronces de Azaila». A.E.A.A, III, Madrid.

CABRÉ DE MorÁn, E. (1984): «Notas para el estudio de las espadas de tipo Arcóbriga». Juan Cabré Aguiló (1882-1982). Encuentro de Homenaje: 151-162. Zaragoza.

CABRÉ DE MorÁn, E. (1990): «Espadas y puñales de la Meseta Oriental en la II Edad del Hierro». Necrópolis Celtibéricas. II Simposio sobre Celtíberos: 123-126, (Coord. Burillo, F. et alli). Zaragoza.

CABRÉ DE MorÁn, E. y BAQUEDANO BELTRÁN, M. I. (1997): «El armamento céltico de la II Edad del Hierro». La Guerra en la Antigüedad. Una aproximación al origen de los ejércitos en Hispania: 240-259. Madrid, Ministerio de Defensa.

CAmpano, A. y SAnZ Mínguez, C. (1990): «La necrópolis celtibérica de «Fuentelaraña», Osma (Soria)». Necrópolis Celtibéricas. II Simposio sobre Celtíberos. (Coord. Burillo, F. et alli), 65-74. Zaragoza.

Cerrillo, E. y Herrero, G. (1992): Ruinas romanas de Caparra. Badajoz, Patrimonio Histórico Extremeño. 
CunLiffe, B. (1993): The Roman Baths. A view over 2000 years. Bath, Bath Archaeological Trust.

GarCía Merino, C. (1984): «La ciudad de Uxama. Nuevos datos para la romanización de Soria». Actas del I Simposium de Arqueología Soriana (Soria 1982): 377-399. Soria.

García Merino, C. (1995): Uxama I. Campañas de 1976 y 1978: Casa de la Cantera, Casa del Sectile, «El Tambor». Madrid, Instituto de Conservación y Restauración de Bienes Culturales.

JIMENO MARTíNEZ, A. (1993): «Numancia». Leyenda y arqueología de las ciudades prerromanas de la península ibérica, vol. II: 119-134. Madrid, M.A.N.

Jimeno MarTíneZ, A. (1994): «Investigación e Historia de Numancia». El Museo Numantino. 75 años de Historia de Soria, (J.L.Argente, ed.), Soria: 25-62.

Jimeno MARTíNeZ, A. (1996): «Numancia: Relación necrópolis-poblado». Archivo Español de Arqueología, 69: 57-76.

Jimeno, A.; Revilla, M.L.; De la torRe, J.L.; Berzosa, R. y MARTínez, J.P. (2002): Numancia, guía del yacimiento. Soria, Asoc. de Amigos del Museo Numantino y Junta de Castilla y León.

LENERZ-DE WILDE, M. (1991): Iberia Céltica. Archäologische Zeugnisse Keltischer Kultur Auf der Pyrenäenhalbinsel. Stuttgart.

LORRIO, A. (1993): «El Armamento de los Celtas hispanos». En Almagro-Gorbea, M. y Ruiz Zapatero, G. (eds.): Los Celtas. Hispania y Europa: 285-326. Madrid.

LORRIO, A. (1994): «La evolución de la panoplia celtibérica». Madrider Mitteilungen 35: 212-257.

LORRIO, A. (1997): Celtíberos. Complutum, Extra no 7. Madrid.

MÉLIDA, J.R. (1917): «Adquisiciones del Museo Arqueológico Nacional. Notas descriptivas, II. Adquisiciones del Estado». R.A.B.M., XXXI. Madrid.

MÉLIDA, J.R. (1918): «Adquisiciones del Museo Arqueológico Nacional en 1917. Notas descriptivas (conclusión). II. Adquisiciones del Estado». R.A.B.M., XXII. Madrid.

MORENAS DE TEJADA, R. (1916): «Divulgaciones arqueológicas: las ruinas de Uxama». Revista Por esos Mundos: 605-610, Madrid.

Morenas de Tejada, R. (1916): Memorias del Informe sobre Uxama, al Sr. Presidente de la Junta de Excavaciones.

PASTOR EIXARCh, J. M. (1998): «Estandartes, insignias y heraldos ibéricos y celtibéricos» Emblemata, $n^{\circ}$ 4. Zaragoza: 11-48.

PÉREZ CASAS, J.A. (1990): «El armamento». Necrópolis Celtibéricas. II Simposio sobre Celtíberos: 115-122. (Coord. Burillo, F. et alli). Zaragoza, Diputación de Zaragoza.

QUESADA SANZ, F. (1997): El armamento ibérico. Estudio tipológico, geográfico, funcional, social y simbólico de las armas en la cultura ibérica (siglos VI- I a.C.). Montagnac, Editions Monique Mergoil.

SCHÜLE, W. (1969): Die Meseta kulturen der iberischen. Berlín.

TARACENA, B. (1941): Carta Arqueológica de España. Soria. Madrid.

THULLIER, J. P. (1989): Les strigila de l'Italie Antique. RA

UlBeRT, G. (1984): Cáceres el Viejo. Madrider Beiträge, 11. Madrid, Deutsches Archäologisches Institut.

ZAPATERO, J.M. (1968): «Un adelantado de la exploración arqueológica soriana: Ricardo Morenas de Tejada». Celtiberia, $\mathrm{n}^{\circ}$ 35: 57-86, Soria.

\author{
DOCUMENTACIÓN DEL ARCHIVO HISTÓRICO DEL MUSEO DEL EJÉRCITO: \\ - Legajo 13/ Ex. 39. \\ - Legajo 13/ Ex. 22.
}

